International Journal of English Language Studies (IJELS)

ISSN: 2707-7578

DOI: $10.32996 /$ ijels

Website: https://al-kindipublisher.com/index.php/ijels

\title{
Metonymic Words and Expressions Characteristic of American English
}

Elnara Putayeva

Teacher of English language, Ph.D. Student, Chair of Linguoculturology, Azerbaijan University of Languages, Baki,

Azerbaijan

Corresponding Author: Elnara Putayeva, E-mail: pedaqoji.ing.fr@mail.ru

ARTICLE INFORMATION ABSTRACT

Received: September 12, 2020

Accepted: October 25, 2020

Volume: 2

Issue: 4

DOI: 10.32996/ijels.2020.2.4.7

\section{KEYWORDS}

American English, metonymic expressions, variety, ethnic minorities, racial differences
When a particular metonymic word or expression is used, it is necessary to have certain cultural and historical knowledge in order to understand what is concealed within these metonymic expressions. Sometimes these metonymic expressions reveal the variety and characteristic features of a culture and give an idea of its being different from others. In the following paper the main intention is to analyze metonymic expressions in American English and to indicate variety that they bring to the speech of language carriers. Metonymy is also used in everyday language in order to give a more colorful and precise expression to ideas. Metonymies are approached as conceptual processes of extension, i.e. they are not so much relationships between words as relationships between concepts. It is interesting to note from a methodological point of view that while research on metaphor, cognitive or otherwise, has been able to focus on its object of matter without necessarily considering metonymy, things are quite different when metonymy comes under analysis. People with resembling cultural backgrounds and many similarities in common may share similar metonymic expressions, but for those who do not have the same cultural background it could sound like a challenge. Metonymy is accordingly a relevant linguistic device that plays a key role in the study of language and culture, and in understanding the speech of people from different cultures. The variety that these expressions cover may range from proper names to names of food and meals.

\section{Introduction}

Metonymy is a figurative means of speech in which something is called by another name that is related in meaning to the original concept. There are numerous words both in literary discourse and everyday language that are considered to be metonyms. Authors of literary works have widely used metonymy for many different reasons. One primary reason is simply to address something in a more poetic and unique way. Another reason is that, it can add to the complexity of meaning drawing the reader's attention to the hidden meaning. As it seems, metonymy is relevantly helpful to make statements more expressive and legible.

A metonymic expression may consist of two or more related words and is intentionally used to reveal the meaning a user wants to emphasize. There must be a meaningful relationship between the parts of an expression and the notion this word combination is related to. The diversity and wide variety of these relationships can cause some difficulties in delivering the idea that is intended to be conveyed by metonymic expressions. In the following paper some of these relationships are indicated, such as "part for whole", "whole for part", "time for action", "place for institution", "author for his writings", "history instead of events", etc.

K C AL-KINDI CENTER R D FOR RESEARCH Your gatewoy to world-class research
Published by Al-KindiCenter for Research and Development. Copyright (c) the author(s). This is an open access article under CC BY license (https://creativecommons.org/licenses/by/4.0/) 


\section{Literature Review}

One of the most controversial issues in metonymy research is what we admit considering that they are realizations of conceptual metonymies. At the early stages of the Conceptual Metaphor Theory (Johnson 1987, Kovecses 2002, Lakoff 1987, Lakoff and Johnson 1980, 1999, Lakoff and Turner 1989, Turner 1987), there was the great tendency of discussing a particular conceptual metaphor and then show its existence by presenting linguistic metaphors. Nevertheless, in more recent years, linguists such as Cameron (1999b, 2003, 2007), Cameron and Deignan (2003), Musolff (2004), Semino (2008), Semino et al. $(2002,2004)$, Steen $(1994,1997)$ and others have been engaged in reversing this tendency by analysing "real" data as the one offered by different corpora.

The distinction of metonymy as for Kriskovic Tominac as a conceptual tool has opened a new sphere of research in cognitive linguistics and pragmatics. Metonymic patterns are effective in speech processes at the level of reference, or predication. The aim of this paper is to study the role of metonymy in spoken discourse and in mass media. Case analyses of expressions used as metonymies following the pragmatic typology of metonymic functions are presented in this research. The processes are facilitated by metonymic mapping connections existing between domains or sub-domains in the same functional domain. All these aspects of metonymic mappings are imposed in complex assumption processes in spoken discourse. In most cases, metonymic mappings are also a part of utterance interpretation.

As for Mario Brdar, metonymy is a pervasive aspect of spontaneous as well as reflective linguistic performance and its cognitive and communicative role needs to be adequately attended to. The paper aims to offer a new pattern of metonymy based on the theoretic approach to communication. First, we present an overview of selected existing accounts of metonymy put forward by cognitive linguists. We also critically address the existing relevance-theoretic models, in attempting to remedy these shortcomings and we develop a fully inferential relevance-theoretic account intended by a concept literally denoted by metonymic expressions (Brdar, 2018).

As for to Rita Brdar, the central issue that concerns us in this chapter is whether metonymy should be conceived as a mapping. It is argued that metonymy should best be treated as an inference-based domain development of the metonymic source, in the course of which domains are adapted to the relevant conceptual measure with regard to their function. In other words, metonymies are not just words or phrases, and they are not necessarily seen as in literal meaning. Adopting a cognitive linguistic approach means that all linguistic cases traditionally called metonymy are reflexes of deeper running conceptual metonymies?

In order to show that America, as a continent, is made up of more immigrants, Irene López-Rodríguez indicated that the specific characteristics of the peoples are also in focus in the description of the various minorities and in the use of such metonyms. The usage of different devices at the stylistical level can generally be used to describe different ethnic minorities and peoples. At the same time, it is possible to use different names of food, fruits and vegetables, which are mostly used by these peoples, and names of national meals that are specific to the cuisine of the same peoples. The food chosen to describe a definite group of people tends to be taken from foodstuffs which are part of the diet of an ethnic group. As there are a lot of ethnic groups living in the U.S., we can observe using a great number of metonymic expressions in AE to stand for these nationalities (López-Rodríguez, 2014)

While speaking of different stylistic devices, Alexsandre Kimenyi also indicated that metaphors and metonymies are traditionally believed to be linguistic expressions which are used figuratively. The difference between metaphors and metonymies is that in the former there is a similarity between the literal and the figurative meaning whereas in the latter it is not similarity but association (Kymenyi).

\section{Methodology}

Discourse analysis has become an increasingly preferred method in many spheres, as it lies in the border of stylistics and rhetorical analysis. In discourse analysis naming of various metonymic patterns are analyzed in relation to their social context. This form of analysis implies the close study of social and discursive situations that often disagree with the traditional scope of rhetoric and literature-such as conversations, meetings, arguments. Language users make stylistic decisions, even if they are not completely aware of doing so. Regarding methods, rhetorical analysis often advances the following way: researchers summarize a text's main idea or arguments, and show its main demands. They then arrange the proof to support each demand. Their goal in doing this extends in considering the process in which an author has successfully engaged various 
audiences. Many researchers follow the classical tradition, and divide evidence. In general, many instances do not comprise metaphorical expressions of human-related terms for the first time checking, so several cases for searching one humanrelated term is definite.

Metonymies are approached as conceptual processes of extension, i.e. they are not so much relationships between words as relationships between concepts. It is interesting to note from a methodological point of view that while research on metaphor, cognitive or otherwise, has been able to focus on its object of matter without necessarily considering metonymy, things are quite different when metonymy comes under analysis. Metonymy is as a rule researched against the background of metaphor. There is no denying that metaphor has acquired far more consideration than metonymy in linguistic research. This has often been pointed out on an involuntary basis, or on the basis of a linguist's personal experience. This latter point can, however, be appropriately and easily aggregated in a colloquial way, e.g. by comparing the number of abstracts or references in various international facts and figures.

In identifying linguistic metonymies, I adopted the content analysis approach. Content analysis method was carried out to categorize and discuss the meaning of words and phrases.

In formulating conceptual metonymies while the model provided in the literature was a helpful guide, I adopted a thematic analysis approach, i.e. I preferred to stay as close as possible to the actual words in the data. Thematic analysis method was used to closely examine the data to identify different metonymic patterns.

\section{Results and Discussion}

\subsection{Some cases with metonymic expressions}

The most used type of metonymic expressions is the combination within parts of which "part for whole" relation is indicated. For example: U.S. instead of America, or England for Great Britain, etc.

Here I will give an example taken from the dialogues between Nelson Mandela and Larry King, where we come across a number of metonymic expressions. Larry King is a well-known interviewer on US television and radio channels. He has been broadcasting "Larry King Live" on CNN since 1985 with politicians, athletes, representatives of art and other celebrities. One of his guests was Nelson Mandela, who was the president of the Republic of South Africa in 1994-1999. The dialogue between them was enriched with metonymic expressions based on simple, and at the same time, complicated word combinations to be obtained.

King: When you look back we only have a minute or so left. Mandela: Yes, go ahead (King, 2006).

L.King's explanation states that this question is related to one's memories, but in terms of time restriction, he reminds that the interviewer should answer briefly. Mr.Mandela's response sounds as if he realizes the situation and understands that he must adapt himself to it. He understands what is required of him, and diplomatically responds, "Yes, go ahead". Here, the metonymic expression is based on the principle of 'part for whole'.

Metonymically expressing people by any particular part of the body is a type of metonymy based on the principle of "part for whole", which also helps to express the idea more clearly. For example:

In the organization we proposed to hire new bloods.

More hands we have, much earlier we finish our work.

We wouldn't fall down into foreign hands (Riad and Vaara, 2011, p.751).

Target concept in the first sentence stands for "intelligent people", in the second and third ones - "employees", and in the last one - "control." It is a case when a part or an element of the whole idea, thing, entity, or something else of this kind may stand for that very thing. Here the main idea is to use only part instead of whole to reveal the intended meaning as well.

In another form of communication, we come across the use of "whole for part" connection. The cases of metonymic expressions with "whole for part" relation between the parts of expressions are not widely spread in AE, but they are somehow observed in everyday speech. Here the main purpose of using such kind of word combinations is to do away with using detailed information or counting of tedious words, as well as to indicate the meaning with the help of general word instead of a specified part. In all these types of expressions the idea intended by the speaker can be easily caught by the context, or "whole for part" relation between the elements of word combinations. 
For example:

To fill a car with fuel

To walk through the door

In the first example, it is intended to fill a specific fuel tank, not a whole car. In the second example, it is intended to go through the doorframe, not the door. In this case, as we have already mentioned, only a certain part of the object is specified, indicating the full name of the object (Drozdz, 2014, p.134).

In another type of metonymic expressions, the conceptual relation of "history instead of events" is reflected. In this case, instead of describing a particular event, it is enough to tell the date of the event that is known to everyone. Again, let's look at an example from L.King's speech:

King: Why didn't we talk about terror, we need 9/11.

I mean you have to have a 9/11 to create, we are after-the fact society, aren't we? (Kriskovic \& Tominac, 2009, p.62).

Here are the well-known attacks of September 11, 2011. Thus, the presenter, who did not need a broader interpretation of the event, referred only to the event as a whole, noting the "9/11" date. The link here also includes a method for showing "history instead of action / event".

Sometimes it can be difficult to translate data into another language or to be understood by non-native speakers. Occasionally, the use of some metonymic expressions in AE by non-native speakers, even in everyday life, requires any person to have a certain cultural background. For example:

It is Korematsu all over again. And there is a reason Korematsu has never been overturned. Are you defining Japanese internment? (Brdar, 2018)

It describes the trial of Korematsu against the United States on the principle of "participant for event". Thus, in May 1942, during World War II, Japanese citizens of the USA were deported to the camps under the instructions of the Civilian Restrictive Order. Fred Korematsu, a Japanese-born American, decided to stay in California and intentionally broke the rules of the US Army Act. He argued that these rules were in violation of the Constitution and violated the Fifth Amendment to the US Constitution. He was arrested and had to fight for years to defend his rights and to prove his commitment to the U.S. Finally, as a result of the many political reforms in the court process, Korematsu declared innocent. Only then, the expression was used in everyday speech, and more commonly referred to as "the Korematsu case" as a metonymic word combination. The literal translation of the expression can be described as "not giving up until one has reached one's will." So it becomes clear that this proper name (Korematsu) is used to stand for continuous struggle, endless wish to define one's innocence, being stubborn in proving something, individual freedom and pursuit of happiness.

The following dialogue provides an indication which requires being aware of American history and geography to understand the metonymy. Here "place for institution" type of relation is revealed.

Costag: The biggest stars, their heads, could go on Mount Rushmore.

O'Brein: Some true, some of them huge, giant, massive, bulbous heads (Kriskovic \& Tominac, 2009, p.66).

As it might be seen from the example, the knowledge of the place name can help us understand the metonymic meaning of the sentence. Mount Rushmore is the top of the mountain with the heads of four famous and prominent US presidents - G. Washington, T. Jefferson, F. Roosevelt and A. Lincoln. It is the place which is directly related to the U.S. As this is a historical place for Americans and "the place of proud" it stands without saying that it might also be considered to be one of the parts of metonymic expressions characteristic of AE. As it is a well-known place for citizens of the country it will not be a contradictory case to reveal the meaning of expressions with it. But for non-native speakers it is advisable to have information about this place in order to clearly understand the meaning a writer or a speaker intends to express. Sometimes cartoons are also created to replace one of these busts with the faces of ordinary people or characters in order to express a certain meaning in the media. At the same time, as this place is an important historical place, shooting processes of different films are carried out here. That is why, Costag used Mount Rushmore to emphasize both the size of the heads and the importance of those described.

As metonymy is considered to be a replacement for a piece, it is advisable to use the name of the manufacturer instead of the product, the name of the container instead of the contained, and the controller for the controlled. People have no difficulty in understanding these expressions, because metonymic expressions help us express not only our linguistic ability 
but also our thoughts and our behavior. Metonymy is a tool that helps people interpret their ideas and make them sound more precise.

\subsection{Proper names characteristic of AE 4.2.1 Toponyms}

Toponyms are a type of proper names which are generally used to indicate a definite place, city, town, street, etc. But as metonymic expressions toponyms can define not only a definite place, but also a number of other meanings related to this place. Some toponyms in AE indicating places, cities, regions, avenues and street names are not used directly in the context, but are considered to express various industrial facilities, famous buildings and residences in these areas. They are generallay related to well-known places where some important buildings, industrial or business centers, buildings of government are situated.

Let's look at the examples in the following order: The name of the place - the literal meaning of the toponym - metonymical meaning

Beverly Hills - The land of the rich in Los Angeles - rich and famous people

Broadway - Street in New York - American Theater

Cooperstown - District in New York - National Baseball Museum in New York

Holywood - Region in Los Angeles - American film industry

Houstin - City in Texas - NASA Space Research Center

$K$ Street - Street in Washington D.C.- A collection of organizations that have the power to influence decisions made by the government and legislators in the United States

Madison Avenue - Street in New York - American advertising industry

Wall Street - Street in New York - American Financial Business

As we see, they are definitely known to users and thier meanings are not difficult to define. That is the main reason why they are not generally used to indicate definite streets, places, cities, or others, but instead they serve to show buildings or centres, museums, theatres situated there. As all these regions, cities, streets and avenues are well-known for specific purposes the value of metonymic usage of these toponyms is the revealing of any idea to the audience more clearly and precisely instead of using long phrases to clear up the intended meaning.

\subsubsection{Special groups of people}

One of the other trends in the use of metonymy in AE is to name special groups of people who have played a significant role in the history of states or in the formation of the nation. Let's try to prove our viewpoints with examples:

Boat people - Southeast Asian immigrants who came to the U.S. after the Vietnam War.

The two chapters provide a sensitive insight into the human, social, and ideological interstices between the trauma of the "boat people" and the types of musical productions (From Cambridge English Corpus).

Some of them have escaped for their lives and have become those tragic people known as the boat people

This is a special phrase characteristic of AE, because It refers to a definite group of people immigrating to the U.S.; and as it describes the exact period and their way of travelling it makes them different from others and easy to define as well.

Coyotes - Criminals and illegal immigrants in the US.

Coyote is a colloquial word used to describe people smuggling across borders of U.S. while breaking immigration laws. It includes bringing human beings into the country and unlawful transportations of immigrants already in the U.S. The word "coyote" is used to describe a person that employed Mexican immigrants for labor in the U.S. During the period when the United States had a great need for workers, the first form of coyote was taken place. The Coyote's main purpose is to hire Mexicans by traveling to Mexico and transporting them to the U.S. or hire the workers when they arrive in the U.S. Here the "coyote" is directly related to the processes going on in the U.S. and it cannot but enter the word stock of AE.

The Fifth column - a small group of people who betray instead of being faithful

In October 1936, in the hostilities of the Spanish Civil War, the nationalist General Emilio Mola and his defenders surrounded Madrid with four columns of troops. E. Mola claimed he had additional troops within the city and predicted that Madrid would fall as his four columns of rebel troops were joined by another "hidden column" of supporters within it. The claim was reported in the New York Times and explicit mention of the hidden troops as the 'fifth column' was reported in the Fitchburg Sentinel newspaper, on 14th October 1936: The term has turned into use after a while and is now often used more generally, to mean a traitor or spy. Even Ernest Hemingway wrote a play called 'The Fifth Column' in 1937, in which he mainly expressed his opposition to the Spanish regime as well. This expression gained widespread popularity after this book was published, and it was often applied to supporters of foreign seizers. The Fifth Column penetrated both into political 
and literal life of Americans, for being related to the historical and political processes and for founding its reflection in some literal works.

Founding Fathers - Founders of the US and its Declaration of Independence (George Washington, John Adams, Thomas Jefferson, Alexander Hamilton, James Madison, etc.).

The Founding Fathers of the United States, or simply the Founding Fathers, were a group of leaders of the U.S. who managed to unite the Thirteen Colonies, won the War of Independence, drafted and signed the Declaration of Independence, founded a frame of a new government, etc. These remarkable individuals made a great contribution to the history of the nation and were originally referred to as the "fathers" of the country. Founding Fathers is such a metonymic expression that one does not need a lot of evidence to prove its being highly connected to both Americans and AE as a language.

Yankees - The meaning of this expression may vary depending on the context. Although outside the U.S.this word is used to describe Americans, in the U.S. the word is used to describe the "new English" who came to the newly discovered territories.

Many etymological variants have been proposed for Yankee, but its origin is still considered to be uncertain. The term "Yankee" has several interrelated meanings, all referring to people from the United States; its various senses depend on the context. Elsewhere in the United States, it largely refers to people from the Northeastern states, but especially those with New England cultural ties. Outside the U.S. this word is used informally to refer to any American. It is especially popular among Britons, Irish, and Australians.

Its sense is sometimes more cultural than geographical, emphasizing the beliefs and traditions of people who brought their culture when they settled outside New England. The term Yankee can have many different meanings within the U.S. that are contextually and geographically dependent. Traditionally, Yankee was most often used to refer to a New Englander descended from the original settlers of the region. By the mid-20th century, some speakers applied the word to any American with a specific focus still on New England.

E. B . White humorously draws his own distinctions of the usage of this word:

To foreigners, a Yankee is an American.

To Americans, a Yankee is a Northerner.

To Northerners, a Yankee is an Easterner.

To Easterners, a Yankee is a New Englander.

To New Englanders, a Yankee is a Vermonter.

And in Vermont, a Yankee is somebody who eats pie for breakfast. (Bull, 2015)

Red power is a contradiction of black power, which is used to denote the power of blacks, and that Indigenous Indians are fighting for their rights.

The history of the Red Power movement began in 1944 and was established to lobby for Native American rights in the US. They had three goals:

Self-determination, tribal sovereignty, improved Native American living conditions. All these elements are considered to be related to the Native Americans demands to gain their independence. Here the main idea is compare the power of indigenous people describing it with the adjective "red" which is one of the way's referring to this ethnic group because of their racial characteristics.

Uncle Tom is the protagonist of the story of "Uncle Tom Cabin" against slavery and is a theory in psychology as well. It refers to coping skills where individuals prefer to stay passive while confronting with a threat and concealing their true thoughts and feelings. The term "Uncle Tom" comes from the title character of Harriet Beecher Stowe's novel, where the African American slave Tom is beaten to death by a rude white master for refusing to betray the two other slaves.

In the American racial context, "Uncle Tom" is a term for African-Americans that hide their ethnic outlooks with the purpose of being accepted into the mainstream. Especially during slavery, African Americans used passivity and servility for the selfpreservation. In a broader context, the term may refer to a minority's strategy of coping with oppression from socially, or culturally dominant groups involving aggression of feelings and even identification leading to forced assimilation of the cultural minority. As "Uncle Tom" is a specified character of Americans it goes without saying that it will obtain some rhetoric meanings while being used in the speech and will enlarge its ways of interpretations (Kimenyi, pp.6-26).

All these phrases and word combinations are somehow related to the history of the U.S. or to some definite events or processes taken place throughout the developing process of the country. One cannot define the meaning of such kinds of metonymic expressions without knowing the processes these expressions are related to, or it might bring some difficulties to understand what the speaker or writer intends to reveal by using these word combinations. We intend to indicate that these metonymic expressions are especially characteristic of $A E$, because of these word combinations either being directly related to the U.S. history, or being used mainly by the native speakers of AE. 


\subsection{Metonymic expressions related to ethnic and racial differences}

At the stylistical level, some devices can generally be used to describe different ethnic minorities and peoples. At the same time, it is possible to use different names of food, fruits and vegetables, which are mostly used by these peoples, and names of national meals that are specific to the cuisine of the same peoples. The food chosen to describe a definite group of people tends to be taken from foodstuffs which are part of the diet of an ethnic group. As there are a lot of ethnic groups living in the U.S., we can observe using a great number of metonymic expressions in AE to stand for these nationalities. For example: in AE the French are called cheese-eaters, baguette-eaters, butterfingers; the English - roastbeefs, beef-eaters, tea-bags, tea sippers; the Irish - potato-eaters, Guiness-drinkers; the Scots - porridge-dribblers, ginger baws; the Germans - chese-eaters; the Norwegians - fish-eaters, salmon-eaters; the Italians - meatballs, macaroni; the Japanese - sushi-eaters, the Chinese insect-eaters; the Vietnamese - dog-eaters, the Koreans - dog-munchers; the Indians - curry-munchers, curry-s/urper; the Arabians - dusty-nuts; the Australians - can-eaters, the New Zealanders - kiwis, etc. (López-Rodríguez, 2014, pp.17-18).

In order to show that America, as a continent, is made up of more immigrants, the specific characteristics of the peoples are also in focus in the description of the various minorities and in the use of such metonyms. So because the native Indians eat the internal organs of more and more different animals, they are gut-eaters; those with European ancestors are hot-dogeaters, hamburger munchers; African-Americans are watermelons, melons, chicken-eaters; the Jews - Kosher-eaters, etc. One of the interesting facts that emerges here is that the people of Hispanic origin are of different races, and even this feature of theirs is reflected in the metonyms to which they belong. For example: black beans - black Spaniards, green beans - a mixture of people of Irish and Spanish descent, white beans - white Spaniards, coffee beans - Colombians, jumping beans - people of Spanish descent who left their homeland and moved to the U.S. and so on (López-Rodríguez, 2014, pp.18-19).

However, discriminatory metonyms are not limited to food names. Traditionally in the U.S. there are 5 major racial differences in skin color (black, brown, red, white and yellow), which can create a parallel relationship between these colors and different foods at the metonymical level. This is also considered to be a case of metonymy in which an element may stand for a phenomenon to which it carries some degrees of association. We see that the races are also called as chocolate for the Black, cinnamon for the Brown, cherries for the Red, flour for the White, lemon for the Yellow. Since the Yellows belonged mainly to the Asians, they were yolked, butterheads; since the Native Indians were considered redish, they were apple and raddish; Whites - marshmallows, milkhead, whitebread, flourbag, yoghurt; Blacks - burnt crackets, cocoa, chocolate; Brown or mixed races are also described as white chocolate, chocolate-covered marshmallows (López-Rodríguez, 2014, pp.20-21). As reflected in metonymical hierarchy, dark skinned people are distinguished from lighter ones to darker ones, or vice versa. Therefore, similar description may be applied to the expressions with chocolate considering its tones of color.

The traditional subdivision of races is based on skin colors. Here, the color spectrum comes to the scene to refer to the names of either ethnic or racial groups. The interesting fact is that the gradation of skin colors and the mixture if racial characteristics may be conveyed by means of colors of certain foods or fruit. There we can clearly observe a tendency of adaption to different cultures or even some features of interracial connections. As examples, we would rather to indicate egg, coconut and banana. For being yellow on the outer skin bananas correspond with the skin color of Asian people living in the Western part of the country. As an egg may consist of the white and yolk, which corresponds to the white people related with Asian culture as well. As for Hispanics, who are assimilated to the white culture might be considered to be coconuts. The metonymic relation is of its being white inside as for cultural features, and being brown outside as for skin color.

Sometimes, even metonymic expressions, arranged according to the form in which meals are cooked, are used in speech to describe different ethnic minorities. Foods can be eaten undercooked, half-cooked, or well-cooked. In other words, food can be eaten either green or ripe, or even when it has gone off. All these above-mentioned cases of different states of food consumption have made grounds for the metonymic use of expressions referring to different ethnic groups in the U.S. For example, any type of food which is undercooked, in AE obtaines a figurative form to describe whites as raw. Expressions such as "overcooked, fried, burnt" (baked, roasted, deep fried, burned), which are supposed to be the opposite, are considered to be stylistic devices describing blacks or local Indians. In other cases, the combination of these two cooking processes is used within the metonymic combinations that apply to members of mixed type of races (half-cooked, half-baked) (LópezRodríguez, 2014, pp.21-22).

The above-mentioned examples show that the word chosen to create a metonymic expression may highlight eating traditions (potato-eaters, insect-eaters), physical characteristics and skin color (burnt-crackers, white bread), job qualifications 
(porridge-dribblers), way of immigration (jumping beans), interracial relationships (half-baked), etc. Through these metonymic expressions people are socialized linguistically and indicate these differences in certain matters, such as food.

\section{Conclusion}

The objective of the research is to indicate cultural variability of different nations living in the US with the help of various metonymic expressions they use in everyday life, in mass media, in literary works, etc. Metonymy is considered to be one of the key styles to create variations in literary texts and in meaning. The use of words and word combinations and certain syntactic structures in AE can make it difficult for non-native speakers to understand them. To our viewpoint, the metonymy that any author uses in his writings should be considered not just a random sequence of words but also a linguistic reflection of conceptual metonymy in the language. Many of these types of metonymies are conceptual metonymies which can also be regarded as an indispensable form of expressions in everyday life.

From the above mentioned, it is possible to conclude that language and culture are linked in different ways and these relationships can be explored from different aspects. Recent investigations in cognitive linguistics allow us to analyse the interrelationship between language and culture both from a universal aspect and from the aspect of variability that cultural differences bring. Since people from different cultures do not use their conceptual abilities equally, even stylistic patterns that can be considered universal are to make variations with their own characteristics. Due to the differences in the history and cultural characteristics of different nations, the conceptual metonymies are shaped according to each different culture. Metonymy and its rhetorical function help the representatives of different cultures understand the meaning of these expressions at different times when various cultures are obliged to "meet".

For future research it is recommended to pay attention to the analysis of correlation of language and culture from both universal aspect and from the aspect of variability this correlation can cause. As language and culture are inseparable units they can surely be analyzed from different angles of linguistic analysis. As the historical, social, cultural, and other various aspects of this kind can differ from nation to nation, different conceptual metonymies should be investigated according to these very differences. Metonymy as a rhetoric and stylistic device, and as a phenomenon functioning cognitively and pragmatically can help us to utilize different types of means of expression in the environment where representatives of various cultures come into connection.

\section{Acknowledgements}

I wish to express my deep gratitude to my research Supervisor, Professor, Masmakhanim Gaziyeva. Her exact attention to details, patient guidance, enthusiastic encouragement, useful critiques of this research work and great knowledge has been an inspiration to the final draft of this project.

\section{References}

[1] [1] Brdar, M. (2018). Novel Metonymies, wine and wineskins, old and new ones. Jezici i culture u vremenu i prostoru, VII/1, $123-134$.

[2] [2] Bull, R. (2015). Does Yankee mean New Yorker or Northerner in general? quora.com/Does-Yankee-mean-New-Yorker-orNortherner-in-general

[3] [3] Dróżdż, G. (2014). Metonymic extension as the process underlying the change of count and mass properties of nouns. Extension and its Limits, 83-109.

[4] [4] Hilpert, M. (2006). Chained Metonymies in Lexicon and Grammar: a Cross-Linguistic Respective on Body Part Terms. members.unine.ch/martin.hilpert/CMLG.pdf

[5] [5] Kimenyi, A. (2007). Metaphors and Metonymies in Ethnic Studies. www.kimenyi.com/Metaphors by Kimenyi[1].pdf

[6] [6] King, L. (2006). Nelson Mandela One-on-One. CNN, May 16, transcripts.cnn.com/TRANSCRIPTS/0005/16/lkl.00.html.

[7] [7] Kriskovic, A. \& Tominac, S. (2009). Metonymy based on cultural background knowledge and pragmatic inferencing: evidence from spoken discourse. Fluminensia, 2 (21), 49-72.

[8] [8] López-Rodríguez, I. (2014). Are We What We Eat? Food Metaphors in the Conceptualization of Ethnic Groups. Linguistik Online, 69(7), 3-36.

[9] [9] Riad, S. \& Vaara, E. (2011). Varieties of National Metonymy in Media Accounts of International Mergers and Acquisitions. Journal of Management Studies, 48(4), 737-771. 